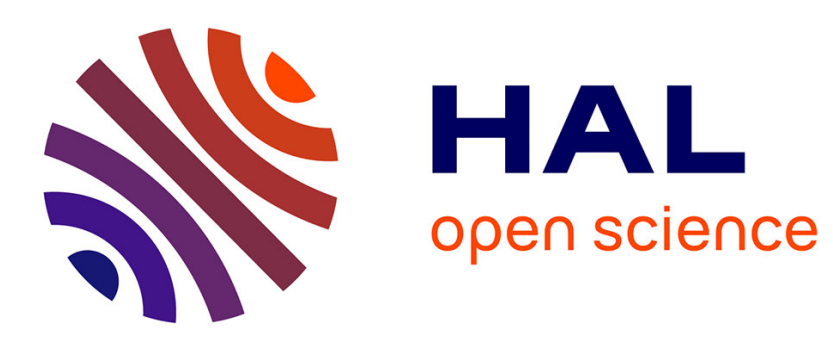

\title{
The latitude dependence and probability distribution of polar mesospheric turbulence
}

\author{
M. Rapp, E. Becker, B. Strelnikov, F.-J. Lübken
}

\section{To cite this version:}

M. Rapp, E. Becker, B. Strelnikov, F.-J. Lübken. The latitude dependence and probability distribution of polar mesospheric turbulence. Atmospheric Chemistry and Physics Discussions, 2006, 6 (6), pp.12199-12216. hal-00302316

\section{HAL Id: hal-00302316 https://hal.science/hal-00302316}

Submitted on 28 Nov 2006

HAL is a multi-disciplinary open access archive for the deposit and dissemination of scientific research documents, whether they are published or not. The documents may come from teaching and research institutions in France or abroad, or from public or private research centers.
L'archive ouverte pluridisciplinaire HAL, est destinée au dépôt et à la diffusion de documents scientifiques de niveau recherche, publiés ou non, émanant des établissements d'enseignement et de recherche français ou étrangers, des laboratoires publics ou privés. 
Atmos. Chem. Phys. Discuss., 6, 12199-12216, 2006 www.atmos-chem-phys-discuss.net/6/12199/2006/

(C) Author(s) 2006. This work is licensed under a Creative Commons License.

Latitude dependence of polar turbulence

M. Rapp et al.

\section{The latitude dependence and probability distribution of polar mesospheric turbulence}

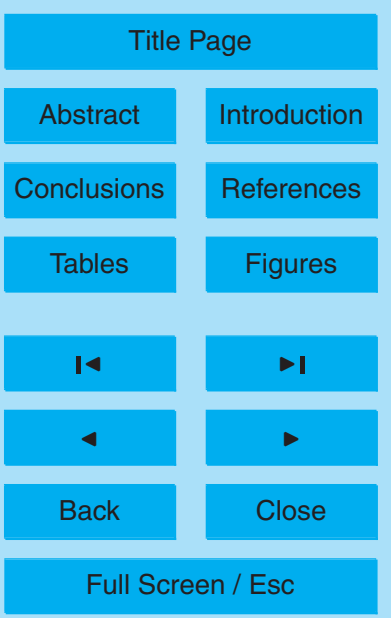

M. Rapp, E. Becker, B. Strelnikov, and F.-J. Lübken

Leibniz Institute of Atmospheric Physics, Schlossstr. 6, 18225 Kühlungsborn, Germany

Received: 25 September 2006 - Accepted: 22 November 2006 - Published: 28 November 2006

Correspondence to: M. Rapp (rapp@iap-kborn.de)

Full Screen / Esc

Printer-friendly Version

Interactive Discussion 


\section{Abstract}

We consider in-situ observations and results from a global circulation model to study the latitude dependence and probability distribution of polar mesospheric turbulence. A comparison of summer observations at $69^{\circ} \mathrm{N}$ and $79^{\circ} \mathrm{N}$ shows that mesospheric

5 turbulence weakens towards the summer pole. Furthermore, these data suggest that at both latitudes in about $\sim 70 \%$ of all samples there are non-turbulent altitude bins in the considered altitude range between 70 and $95 \mathrm{~km}$. The remaining $30 \%$ with detectable turbulence show an approximately log-normal distribution of dissipation rates. A low-resolution model version with a gravity wave (GW) parameterization explains the observed latitude dependence as a consequence of a downshift of the breaking levels towards the summer pole and an accompanying decay of turbulent heating per unit mass. When we do not use a GW parameterization but employ a high spatial resolution instead to simulate GW effects explicitly, the model predicts a similar latitudinal dependence with weakening turbulence towards the summer pole. In addition, the model 15 also produces a log-normal distribution of dissipation rates. The simulated probability distribution is more narrow than in the observations since the model resolves at most mid-frequency GWs, whereas real turbulence is also excited by smaller-scale disturbances. The GW resolving simulation suggests a weaker tropospheric GW source at polar latitudes as the dominating mechanism for the latitudinal dependence.

\section{Introduction}

It is well known that the thermal and dynamical structure of the mesosphere and lower thermosphere (MLT) region is mainly controlled by wave-mean flow interaction (Dunkerton, 1978). In the mesopause region, breaking GWs drive a summer-to-winterpole residual circulation, which induces downwelling and adiabatic warming in winter, 25 as well as upwelling and adiabatic cooling in summer. The latter results in the extremely low temperatures at the polar summer mesopause (e.g. Lübken, 1999). Consequently,

Latitude dependence of polar turbulence

M. Rapp et al.

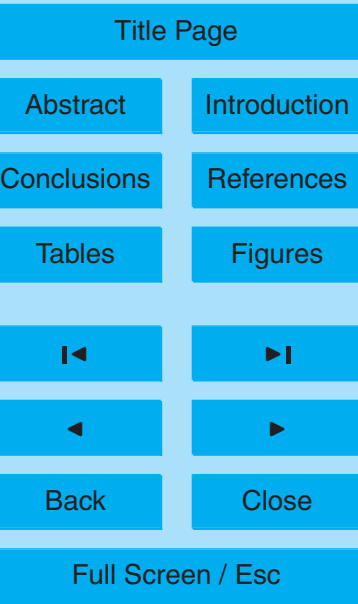

Printer-friendly Version

Interactive Discussion 
detailed knowledge of gravity wave breakdown and the accompanying turbulence is mandatory for a detailed understanding of the dynamics and energetics of the middle atmosphere. While our data base and understanding of gravity wave characteristics has considerably grown over the past decades (see Fritts and Alexander, 2003, for a re-

5 cent review), the available data base concerning mesospheric turbulence has remained scarce. This is mainly because of the experimental difficulties in measuring associated small-scale atmospheric properties, such that our current knowledge mainly rests on the results from a few in-situ soundings (e.g., Lübken, 1997; Lehmacher et al., 2006), and observations with radars which are, however, often difficult to interpret quantita10 tively (e.g., Hocking, 1996; Engler et al., 2005). Since available measurements are concentrated at very few geographical locations (i.e., basically all previous in-situ observations were obtained at $\sim 69^{\circ} \mathrm{N}$ ), information on the latitudinal dependence and the probability distribution of turbulence is very limited.

In this paper we present a comparison of turbulent energy dissipation rates, $\epsilon$, mea15 sured in situ at $\sim 69^{\circ} \mathrm{N}$ and $\sim 79^{\circ} \mathrm{N}$. The observed latitude dependence in mean and variable dissipation rates are compared to results from a mechanistic general circulation model, suggesting a log-normal probability distribution for the dissipation and yielding two distinct mechanisms that both may contribute to the observed latitude dependence.

\section{Experimental results}

In this section we compare the available in-situ measurements of turbulent energy dissipation rates under summer conditions at two geographical latitudes, i.e., at $\sim 69^{\circ} \mathrm{N}$ (including two flights at $68^{\circ} \mathrm{N}$ ) and $79^{\circ} \mathrm{N}$. All experimental values were obtained from analyzing ionization gauge measurements of relative neutral air density fluctuations 25 (Lübken, 1992). In short, turbulent energy dissipation rates, $\epsilon$, are derived from such measurements by converting the relative density fluctuations to power spectra with either Fourier or wavelet-techniques, and then comparing these power spectra to those

\section{ACPD}

6, 12199-12216, 2006

\section{Latitude dependence} of polar turbulence

M. Rapp et al.

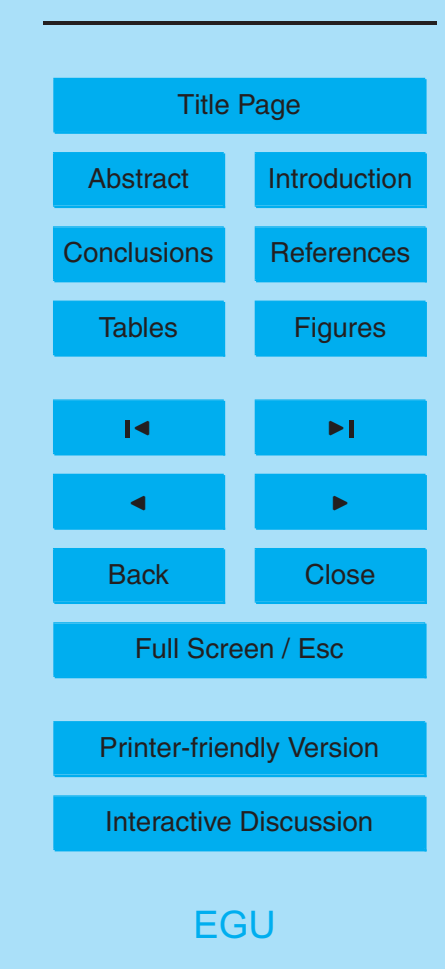


expected from turbulence theory (see Lübken, 1992; Strelnikov et al., 2003, for details). Spectra which clearly do not reveal a "turbulent" shape (i.e., which do not show an inertial subrange characterized by a classical $k^{-5 / 3}$ power law, see e.g. Fig. 2 in Lübken et al., 2002) are discarded as non-turbulent. The data from $\sim 69^{\circ} \mathrm{N}$ were previously 5 presented by Lübken et al. (2002), Müllemann et al. (2003) and Rapp et al. (2004). Some basic information on these flights is summarized in Table 1.

Measurements from $79^{\circ} \mathrm{N}$ were recently obtained during the ROMA-SvalRak (Rocketborne Observations of the Middle Atmosphere at the SvalRak facilities) campaign which took place from 29 June to 6 July 2003 at Ny-Ålesund on Svalbard $\left(79^{\circ} \mathrm{N}, 12^{\circ} \mathrm{E}\right)$. We note that collocated mesospheric temperature measurements performed with a potassium resonance lidar in the summers 2002 and 2003 indicate that this period was a "typical" summer week with no extraordinary events (J. Höffner, private communication, August 2006). The main scientific aim of the sounding rocket campaign was the study of small-scale processes related to neutral and plasma dynamics in the MLT. For 15 more details on this campaign and an initial overview of achieved results see Strelnikov et al. (2006). For this study, we focus on the turbulence measurements obtained during the three sounding rocket flights labeled ROMI01-03 (see Table 1 for details).

In Fig. 1 we present a comparison of all turbulent energy dissipation rates, $\epsilon$ (or heating rates $Q$ ), from the observations at $69^{\circ} \mathrm{N}$ with the new data obtained at $79^{\circ} \mathrm{N}$. 20 This figure suggests that heating rates observed at $79^{\circ} \mathrm{N}$ were on average smaller than those observed at $69^{\circ}$, i.e., most crosses lie to the left of the majority of values indicated by the black diamonds. In addition, it is interesting to note that flight ROMI03 (blue crosses) represents the first in-situ measurement in the polar summer, where not a single altitude bin (here consistently taken as $1 \mathrm{~km}$ for all flights) revealed any 25 turbulent activity.

Given the rather poor statistics of only three sounding rocket flights at $79^{\circ} \mathrm{N}$, we have performed a more in-depth statistical comparison of the turbulent heating rates measured at $69^{\circ} \mathrm{N}$ and $79^{\circ} \mathrm{N}$. We have taken all measured $Q$-values in the entire altitude range between 72 and $95 \mathrm{~km}$ for each latitude and counted how many of these fell into

Latitude dependence of polar turbulence

M. Rapp et al.

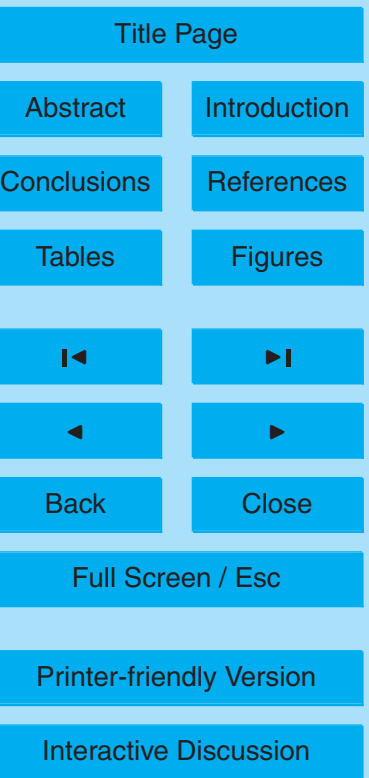


classes with $Q=0$ (i.e., no turbulent spectrum was observed), $0.001 \mathrm{~K} / \mathrm{d} \leq Q<0.01 \mathrm{~K} / \mathrm{d}$, $0.01 \mathrm{~K} / \mathrm{d} \leq Q<0.1 \mathrm{~K} / \mathrm{d}, . ., Q>100 \mathrm{~K} / \mathrm{d}$. The resulting histograms are presented in Fig. 2, where measurements with $Q=0$ are presented as the leftmost vertical bars.

This figure shows several interesting details: first of all both histograms reveal that in 5 about $70 \%$ of all measurements (precisely speaking $67 \%$ at $69^{\circ} \mathrm{N}$ and $80 \%$ at $79^{\circ} \mathrm{N}$ ), observed spectra did not show any evidence for turbulence. The remaining $Q$-values larger than 0 are approximately normally distributed in values of $\log (Q)$, i.e., they approximately reveal a log-normal distribution. Note that we have performed the same type of analysis for the limited altitude range of $82-90 \mathrm{~km}$ yielding essentially the same 10 results (but note that the turbulence occurrence rate is certainly much larger in small altitude ranges, see Rapp and Lübken (2003), Fig. 7, for an altitude profile of the turbulence occurrence rate at $69^{\circ} \mathrm{N}$ ). Mean (median) values of the two distributions for the full altitude range $(72-95 \mathrm{~km})$ are $13.7 \mathrm{~K} / \mathrm{d}(1.6 \mathrm{~K} / \mathrm{d})$ in the case of $69^{\circ} \mathrm{N}$ and $3.2 \mathrm{~K} / \mathrm{d}$ $(0.2 \mathrm{~K} / \mathrm{d})$ at $79^{\circ} \mathrm{N}$, respectively. We note that since the ensembles show an approxi15 mately log-normal distribution, the median values actually provide a better characterization of these data than the means. In order to clarify whether the obtained median values truly indicate that turbulent heating rates at $79^{\circ} \mathrm{N}$ are on average smaller than at $69^{\circ} \mathrm{N}$, we have performed a Student's t-test (e.g., Taubenheim, 1965) on the distributions in $\log (Q)$ and found that the difference between the two median values is indeed significant at the $90 \%$ confidence level.

We note that this result is most probably not an artifact of an improper sampling of a potential tidal signature in mesospheric turbulence: if we assume that the recent MFradar results of Hall et al. (2006) obtained at Troms $\varnothing\left(70^{\circ} \mathrm{N}, 19^{\circ} \mathrm{E}\right)$ are applicable to our measurements at both $69^{\circ} \mathrm{N}$ and $79^{\circ} \mathrm{N}$, we would expect larger dissipation rates between 08:20 UT and 09:23 UT (when measurements at $79^{\circ} \mathrm{N}$ were made) than between 21:21 UT and 01:40 UT (when measurements at $69^{\circ} \mathrm{N}$ were made), i.e., the opposite of what we have observed.

In summary, our measurements imply that a typical occurrence rate of mesospheric turbulent activity at polar latitudes (i.e., both $69^{\circ} \mathrm{N}$ and $79^{\circ} \mathrm{N}$ ) in summer is $\sim 30 \%$, and

Latitude dependence of polar turbulence

M. Rapp et al.

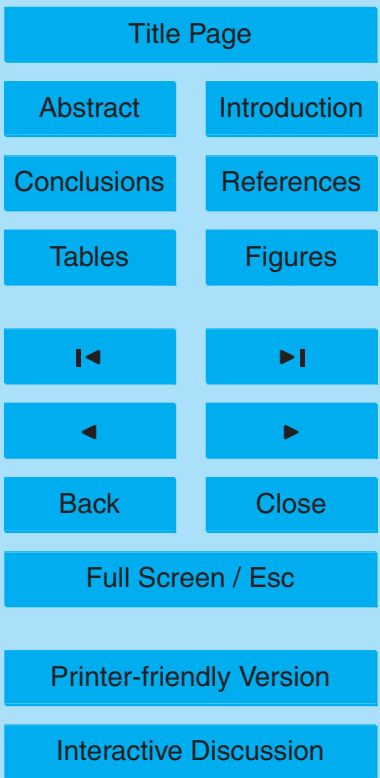

EGU 
that turbulence at $79^{\circ} \mathrm{N}$ is on average weaker than at $69^{\circ} \mathrm{N}$. In the following section, we compare these findings to results from a global circulation model and try to identify the underlying physical causes.

\section{Latitudinal dependence of mesospheric turbulence in a GCM}

5 We employ the Kühlungsborn Mechanistic general Circulation Model (KMCM) which is described elsewhere (e.g. Becker, 2004, and references therein). Note that this model focuses on the principal physical processes creating the most important qualitative features of the dynamical and thermal structure of the atmosphere. Hence we do not aim to provide a one-to-one correspondence to measurements. It is also "only" these general features which we will discuss in this section.

First we use the previous model version with a typical climate-model resolution and completed by a Lindzen-type gravity-wave parameterization (Becker, 2004; Becker et al., 2004). Inspection of Fig. 4d in Becker et al. (2004) already reveals that turbulent dissipation rates in the summer MLT decrease from mid-latitudes towards the 15 pole. In Fig. 3 corresponding profiles of turbulent heating rates at $60^{\circ}$ and $80^{\circ} \mathrm{N}$ are shown along with corresponding profiles of the mean zonal wind.

The mechanism suggested by Fig. 3 is as follows. In the model, the dominating GW that gives rise to wave-mean flow interaction and dissipation in the summer MLT is an eastward propagating wave with a phase speed of $c \sim 30 \mathrm{~ms}^{-1}$. The altitude of the breaking (or saturation) level $z_{b}$ is given by

$z_{b}=3 H \ln (|\bar{u}-c| / \tilde{u})$

where $H$ is the pressure scale height, $\bar{u}$ is the mean zonal wind, and $\tilde{u}$ is a measure of the wave amplitude at the launching level (e.g. Becker, 2004, Eq. 41). Therefore, when launched at $80^{\circ} \mathrm{N}$, this wave will start breaking at a lower altitude than at $60^{\circ}$ due to the weaker mesospheric easterlies. Since the background neutral density is larger at lower altitudes, this implies a weaker dissipation per unit mass at $80^{\circ}$ than at $60^{\circ} \mathrm{N}-$

Latitude dependence of polar turbulence

M. Rapp et al.

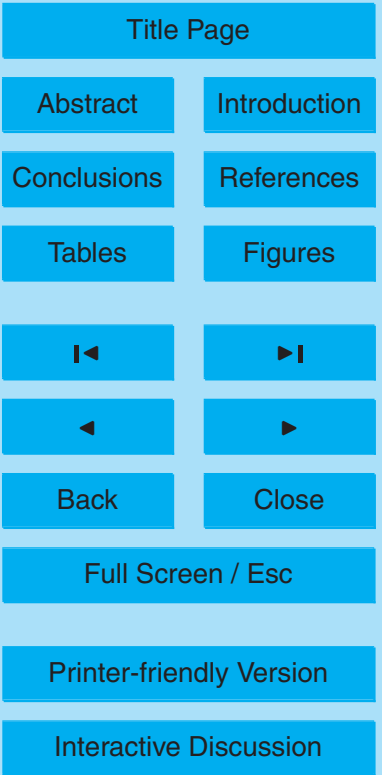


provided the GW source is latitudinally uniform, which is still a common assumption in present-day parameterizations.

General circulation models that employ GW parameterizations along with course spatial resolutions can certainly not provide us with estimates of the short-term vari5 ability of turbulence in the MLT. In order to simulate at least a portion of the observed variability, GWs must be simulated explicitly (e.g. Hamilton et al., 1995). Recently, Becker and Fritts (2006) have presented an extension of KMCM in which they simulated the effects of mid-frequency GWs by increasing the model's vertical resolution to 190 hybrid levels between $0.1 \mathrm{~km}$ and $125 \mathrm{~km}$, and using a horizontal resolution of 10 T85 corresponding to a horizontal grid spacing of 1.4 degree or $162 \mathrm{~km}$. Gravity waves are self-generated by the tropospheric dynamics and their dissipation in the MLT is induced by nonlinear horizontal and vertical diffusion schemes with prescribed vertical profiles of the mixing lengths. Like a conventional model with parameterized GWs, this high-resolution model version produces a climatology which is in general agreement 15 with observations (see Fig. 4 in Becker and Fritts, 2006). As a notable difference to the older model version, the mean dissipation in the summer MLT peaks at higher latitudes, i.e., at $60^{\circ}$ in the model of Becker and Fritts (2006) instead of $45^{\circ}$ in the case of Becker (2004). As a result, the high-latitude mean dissipation rate is in much better agreement with observations. Profiles of mean dissipation rates at $60^{\circ} \mathrm{N}, 70^{\circ} \mathrm{N}$ and $80^{\circ} \mathrm{N}$ along with the mean profile from observations at $69^{\circ} \mathrm{N}$ are presented in Fig. 4.

The latitude dependence in Fig. 4 yields weaker heating rates at $80^{\circ}$ than at $60^{\circ} \mathrm{N}$, consistent with Figs. 2 and 3. But with resolved GWs the maximum dissipation shifts to higher altitudes with increasing latitude, as opposed to the behavior seen in the lowresolution model with a horizontally uniform GW source. This suggests that the selfgenerated tropospheric GW source becomes weaker at polar latitudes such that the "saturation" levels shift upwards (see also Eq. 1). Obviously this overcompensates the effect of a downshift of the "saturation" levels due to reduced mean easterlies. Therefore, the high-resolution simulation implies that a weaker tropospheric GW source at polar latitudes is the dominating mechanism that yields on average decaying dissipa-

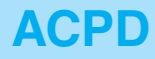

6, 12199-12216, 2006

\section{Latitude dependence of polar turbulence}

M. Rapp et al.

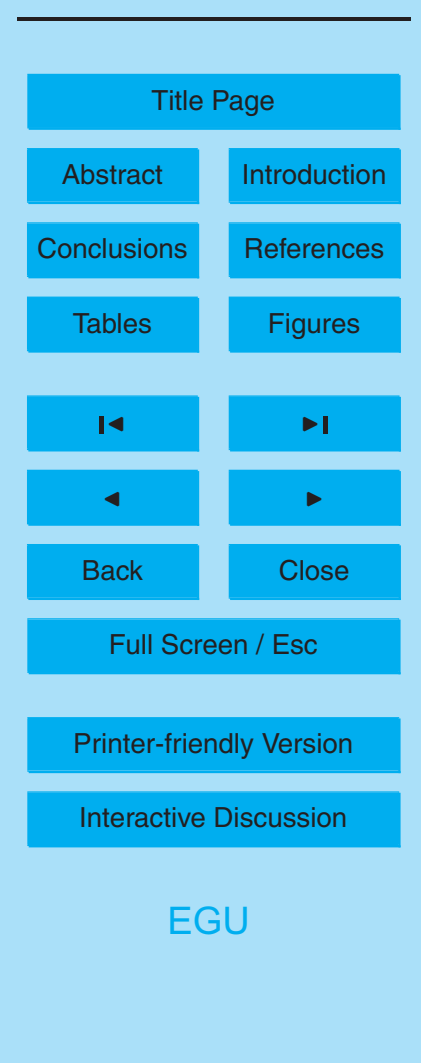


tion rates towards the summer pole.

Next, we analyze the variability of the simulated turbulent dissipation in the summer MLT. Let us consider a representative 4-day sequence of the dissipation at $60^{\circ} \mathrm{N}$ and $0^{\circ} \mathrm{E}$, using model snapshots every 90 min (Fig. 5).

5 It is obvious that a strong temporal variability appears at periods of a few to several hours, i.e., periods of mid and low-frequency GWs which are the smallest features resolved in the model. I.e., the substantial horizontal wind variations owing to the GWs (which are of order of $\pm 50 \mathrm{~ms}^{-1}$ - not shown here) lead to the strong variations of the dissipation rate.

10 As matter of fact, the observed variability of the dissipation occurs at even smaller spatial and temporal scales than in the simulation and consequently attains smaller and larger extreme values. This notion is also supported by the direct numerical simulations of Achatz (2006), where the resolution goes far beyond that of the present model.

We therefore expect that the distribution of the simulated dissipation will be narrower 15 than in the measurements. To quantify this hypothesis, Fig. 6 shows histograms of the dissipation in Becker and Fritts (2006)'s permanent July simulation, using a 60 day time series with model snapshots every 90 min at latitudes of $60^{\circ} \mathrm{N}$ and $80^{\circ} \mathrm{N}$ for altitudes between $70-95 \mathrm{~km}$, and eight equidistant arbitrarily chosen longitudes.

The most striking difference to Fig. 2 is that there are no cases with "zero" dissipation rates, i.e. very small dissipation rates are much less probable than in the real atmosphere. Likewise, also the probability for values higher than $10^{2} \mathrm{~K} / \mathrm{d}$ is much smaller. As expected, the simulated probability distribution is thus more narrow than in the observations. Nevetheless, it confirms a log-normal distribution otherwise.

Concerning the inability of the model to produce a large number of "non-turbulent" altitude bins, we need to consider that the modeled heating rates are actually average values representative of volumes with typical dimensions of a few hundred kilometers in the horizontal, a few kilometers in the vertical, and about $30 \mathrm{~min}$ in time. This needs to be compared to our measurements which are snapshots in both horizontal and temporal dimension (i.e., a few centimeters and $1 \mathrm{~s}$ of flight-time) and are only averaged

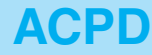

6, 12199-12216, 2006

\section{Latitude dependence} of polar turbulence

M. Rapp et al.

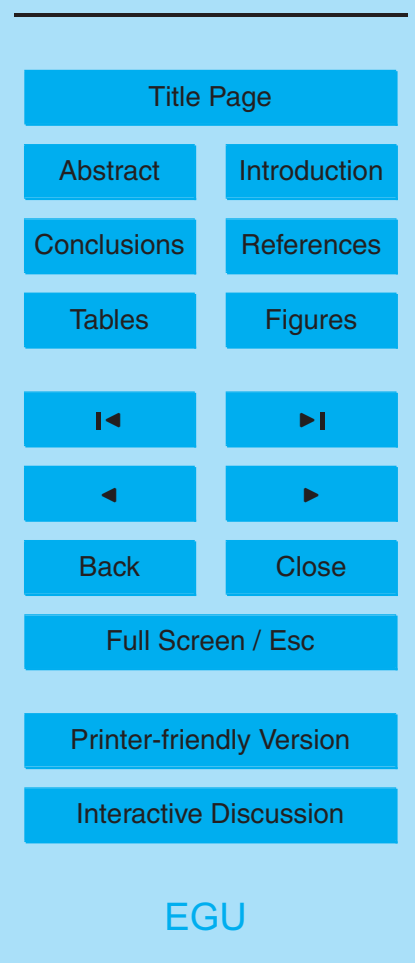


over a vertical scale of at most $1 \mathrm{~km}$. This means that a single model value should actually be considered representative of the mean of a few thousand "real" values. Hence, if $70 \%$ of these values are zero and $30 \%$ do show significant heating rates, then the average of thousands of values should actually be non-zero - as seen in the model. 5 Hence, the missing zero heating rates in the model are not necessarily in contradiction to our observations but can likely be explained by the very different sampling statistics of observations and model.

\section{Conclusions}

We have considered in-situ observations and results from a global circulation model in 10 order to yield insight into the latitude dependence and probability distribution of polar mesospheric turbulence. A comparison of summer observations at $69^{\circ} \mathrm{N}$ and $79^{\circ} \mathrm{N}$ shows that mesospheric turbulence becomes weaker towards the summer pole. At both latitudes, the data sets for the considered altitude range between 70 and $95 \mathrm{~km}$ reveal that about $\sim 70 \%$ of all samples are non-turbulent. The remaining $30 \%$ with 15 detectable turbulence show an approximately log-normal distribution of dissipation rates. Two model runs with either a Lindzen-type GW parameterization or resolved mid-frequency GWs reproduce the general decay of turbulence towards the summer pole. The conventional model concept yields lower saturation levels owing to weaker mean easterlies near the summer pole as a possible explanation. The GW resolving model run, on the other hand, suggests that a weaker tropospheric GW source at polar latitudes is the dominating mechanism for decaying dissipation rates towards the summer pole. Furthermore, an approximate log-normal distribution of turbulent dissipation rates is found, as in the observations. However, because of the limited resolution the simulated distribution is significantly more narrow than in the observations. We also note that the model does not yield a large part of samples with no turbulence at all. At this stage, it appears most likely that the very different sampling statistics of model and observations create this difference. This issue will require our attention in the future.

\section{ACPD}

6, 12199-12216, 2006

\section{Latitude dependence} of polar turbulence

M. Rapp et al.

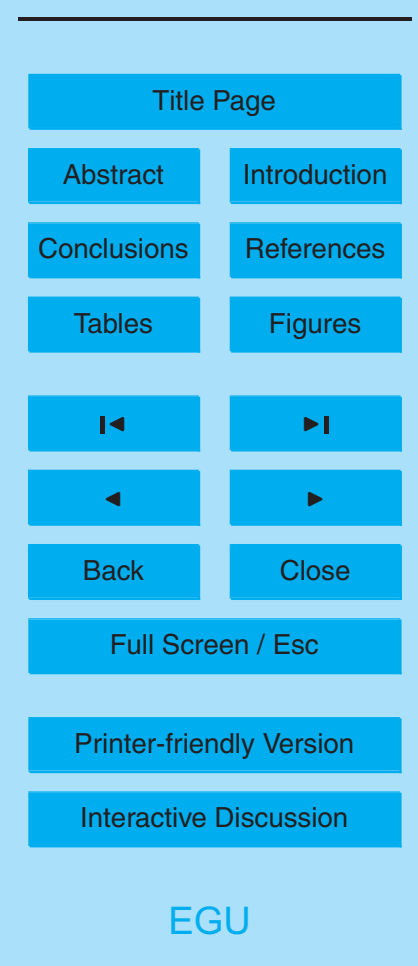


Acknowledgements. For valuable discussions we would like to thank $\mathrm{U}$. Achatz. This project was supported by the BMBF under DLR grants 50 OE 9802 and 50 OE 9901.

\section{ACPD}

6, 12199-12216, 2006

\section{References}

Achatz, U.: The primary nonlinear dynamics of modal and nonmodal perturbations of monochromatic inertia-gravity waves, J. Atmos. Sci., in print, 2006. 12206

Becker, E.: Direct heating rates associated with gravity wave saturation, J. Atmos. Sol. Terr. Phys., 66, 683-696, 2004. 12204, 12205

Becker, E. and Fritts, D. C.: Enhanced gravity-wave activity and interhemispheric coupling during the MaCWAVE/MIDAS northern summer program 2002, Ann. Geophys., 24, 11751188, 2006. 12205, 12206, 12214, 12215, 12216

Becker, E., Müllemann, A., Lübken, F.-J., Körnich, H., Hoffmann, P., and Rapp, M.: High Rossby-wave activity in austral winter 2002: Modulation of the general circulation of the MLT during the MaCWAVE/MIDAS northern summer program, Geophys. Res. Lett., 31, L24S03, doi:10.1029/2004GL019615, 2004. 12204, 12213

Dunkerton, T. J.: On the mean meridional mass motions of the stratosphere and mesosphere, J. Atmos. Sci., 35, 2325-2333, 1978. 12200

Engler, N., Latteck, R., Strelnikov, B., Singer, W., and Rapp, M.: Turbulent energy dissipation rates observed by Doppler MST radar and by rocket-borne instruments during the MIDAS/MaCWAVE campaign 2002, Ann. Geophys., 23, 1147-1156, 2005. 12201

Fritts, D. C. and Alexander, M. J.: Gravity wave dynamics and effects in the middle atmosphere, Rev. Geophys., 41, doi:10.1029/2001RG000106, 2003. 12201

Hall, C. H., Nozawa, S., Manson, A. H., and Meek, C. E.: Tidal signatures in mesospheric turbulence, Ann. Geophys., 24, 453-465, 2006. 12203

Hamilton, K., Wilson, R. J., Mahlmann, J. D., and Umscheid, L. J.: Climatology of the SKYHI troposphere-stratosphere-mesosphere general circulation model, J. Atmos. Sci., 52, 5-43, 1995. 12205

Hocking, W.: An assessment of the capabilities and limitations of radars in measurements of upper atmosphere turbulence, Adv. Space Res., 17, 37-47, 1996. 12201

Lehmacher, G., Croskey, C., Mitchell, J., M.Friedrich, Lübken, F.-J., Rapp, M., Kudeki, E., and Fritts, D. C., Intense turbulence observed above a mesospheric temperature inversion
Latitude dependence of polar turbulence

M. Rapp et al.

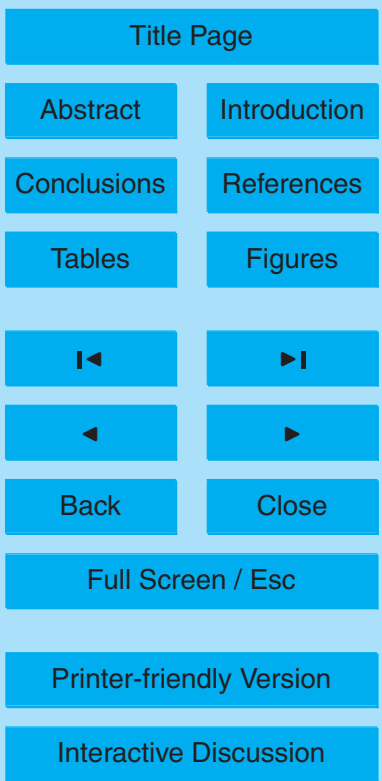

EGU 
at equatorial latitude, Geophys. Res. Lett., 33, L08808, doi:10.1029/2005GL024345, 2006. 12201

Lübken, F.-J.: On the extraction of turbulent parameters from atmospheric density fluctuations, J. Geophys. Res., 97, 20 385-20 395, 1992. 12201, 12202

5 Lübken, F.-J.: Seasonal variation of turbulent energy dissipation rates at high latitudes as determined by insitu measurements of neutral density fluctuations, J. Geophys. Res., 102, 13441-13 456, 1997. 12201

Lübken, F.-J.: Thermal structure of the Arctic summer mesosphere, J. Geophys. Res., 104, 9135-9149, 1999. 12200

10 Lübken, F.-J., Rapp, M., and Hoffmann, P.: Neutral air turbulence and temperatures in the vicinity of polar mesosphere summer echoes, J. Geophys. Res., 107(D15), 4273, doi:10.1029/2001JD000915, 2002. 12202

Müllemann, A., Rapp, M., and Lübken, F.-J.: Morphology of turbulence in the polar summer mesopause region during the MIDAS/SOLSTICE campaign 2001, Adv. Space Res., 31(9), 2069-2074, 2003. 12202

Rapp, M. and Lübken, F.-J.: On the nature of PMSE: Electron diffusion in the vicinity of charged particles revisited, J. Geophys. Res., 108(D8), 8437, doi:10.1029/2002JD002857, 2003. 12203

Rapp, M., Strelnikov, B., Lübken, F.-J., and Fritts, D. C.: Turbulence measurements and implications for gravity wave dissipation during the MaCWAVE/MIDAS rocket program, Geophys. Res. Lett., 31, L24S07, doi:10.1029/2003GL019325, 2004. 12202

Strelnikov, B., Rapp, M., and Lübken, F.-J., A new technique for the analysis of neutral air density fluctuations measured in situ in the middle atmosphere, Geophys. Res. Lett., 30, 2052, doi:10.1029/2003GL018271, 2003. 12202

Strelnikov, B., Rapp, M., Blix, T. A., Engler, N., Höffner, J., Lautenbach, J., Lübken, F.-J., Smiley, B., and Friedrich, M.: In situ observations of small scale neutral and plasma dynamics in the mesosphere/lower thermosphere at 79 N, Adv. Space Res., 38(11), 2388-2393, 2006. 12202

Taubenheim, J.: Statistische Auswertung geophysikalischer und meteorologischer Daten, Akademische Verlagsgesellschaft Geest und Portig K.-G., Leipzig, 1965. 12203

\section{Latitude dependence} of polar turbulence

M. Rapp et al.

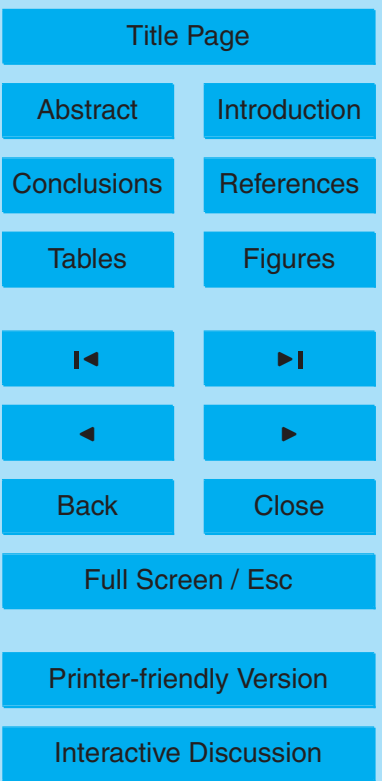




\section{ACPD}

6, 12199-12216, 2006

Table 1. Rocket flights with ionization gauge measurement of turbulence under polar summer conditions.

\begin{tabular}{llll}
\hline flight label & date & time (UT) & launch site \\
\hline NAT13 & 9 Aug 1991 & $23: 15: 00$ & $68^{\circ} \mathrm{N}, 20^{\circ} \mathrm{E}$ \\
NBT05 & 1 Aug 1991 & $01: 40: 00$ & $68^{\circ} \mathrm{N}, 20^{\circ} \mathrm{E}$ \\
SCT03 & 28 July 1993 & $22: 23: 00$ & $69^{\circ} \mathrm{N}, 16^{\circ} \mathrm{E}$ \\
SCT06 & 31 July 1993 & $01: 46: 00$ & $69^{\circ} \mathrm{N}, 16^{\circ} \mathrm{E}$ \\
ECT02 & 28 July 1994 & $22: 39: 00$ & $69^{\circ} \mathrm{N}, 16^{\circ} \mathrm{E}$ \\
ECT07 & 31 July 1994 & $00: 50: 33$ & $69^{\circ} \mathrm{N}, 16^{\circ} \mathrm{E}$ \\
ECT12 & 12 Aug 1994 & $00: 53: 00$ & $69^{\circ} \mathrm{N}, 16^{\circ} \mathrm{E}$ \\
MDMI05 & 6 July 1999 & $00: 06: 00$ & $69^{\circ} \mathrm{N}, 16^{\circ} \mathrm{E}$ \\
SOMI05 & 17 June 2001 & $00: 05: 00$ & $69^{\circ} \mathrm{N}, 16^{\circ} \mathrm{E}$ \\
SOMI12 & 24 June 2001 & $21: 21: 15$ & $69^{\circ} \mathrm{N}, 16^{\circ} \mathrm{E}$ \\
MMMI12 & 2 July 2002 & $01: 44: 00$ & $69^{\circ} \mathrm{N}, 16^{\circ} \mathrm{E}$ \\
MMMI24 & 5 July 2002 & $01: 10: 00$ & $69^{\circ} \mathrm{N}, 16^{\circ} \mathrm{E}$ \\
MMMI25 & 5 July 2002 & $01: 42: 00$ & $69^{\circ} \mathrm{N}, 16^{\circ} \mathrm{E}$ \\
ROMI01 & 1 July 2003 & $09: 23: 00$ & $79^{\circ} \mathrm{N}, 12^{\circ} \mathrm{E}$ \\
ROMI02 & 4 July 2003 & $08: 20: 00$ & $79^{\circ} \mathrm{N}, 12^{\circ} \mathrm{E}$ \\
ROMI03 & 6 July 2003 & $08: 27: 00$ & $79^{\circ} \mathrm{N}, 12^{\circ} \mathrm{E}$ \\
\hline
\end{tabular}

\section{Latitude dependence} of polar turbulence

M. Rapp et al.

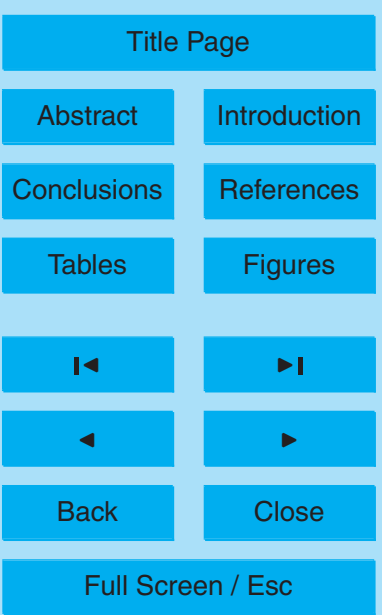

Printer-friendly Version

Interactive Discussion 


\section{ACPD}

6, 12199-12216, 2006

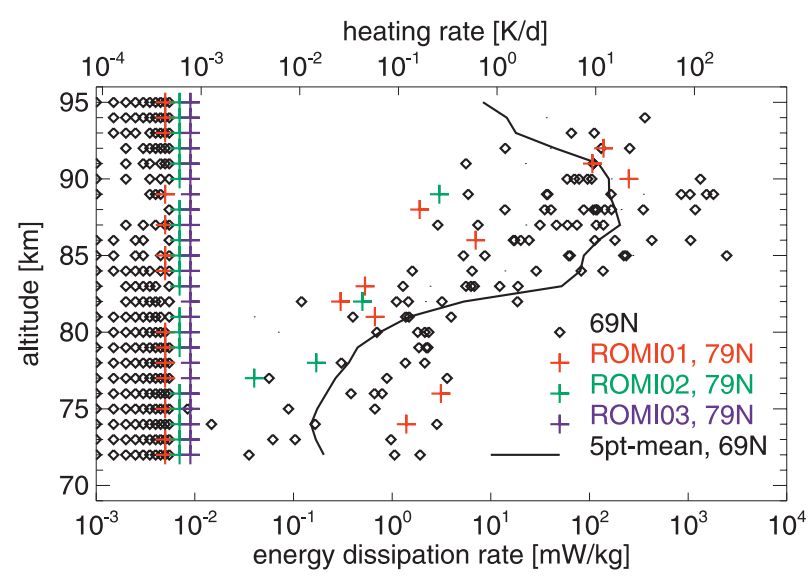

Fig. 1. Overview of all mesospheric turbulent energy dissipation rates measured with the ionization gauge technique at polar latitudes. The black symbols mark observations from $\sim 69^{\circ} \mathrm{N}$. Colored crosses mark the observations from Svalbard $\left(79^{\circ} \mathrm{N}\right)$. Measurements which were identified as "non-turbulent" (see text for further explanation) are indicated on the left ordinate. The black solid line indicates the mean of the observations from $69^{\circ} \mathrm{N}$ and has been smoothed over 5 points. The upper abscissa converts energy dissipation rates $\epsilon$ to heating rates $Q$ using $Q=\epsilon / c_{p}$ where $c_{p}$ is the heat capacity of air at constant pressure.

\section{Latitude dependence of polar turbulence}

M. Rapp et al.

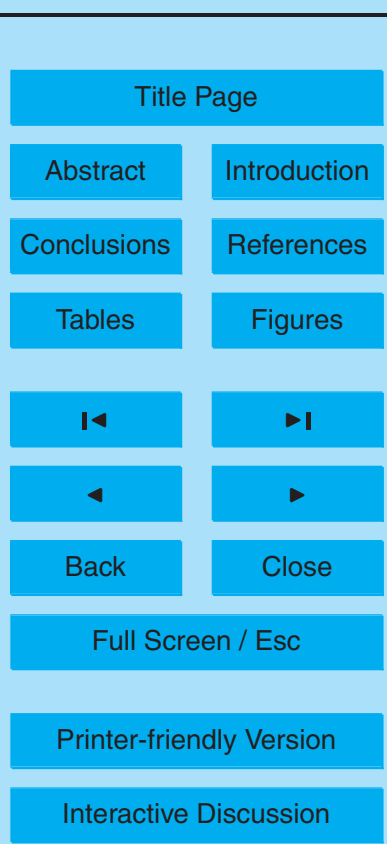




\section{ACPD}

6, 12199-12216, 2006

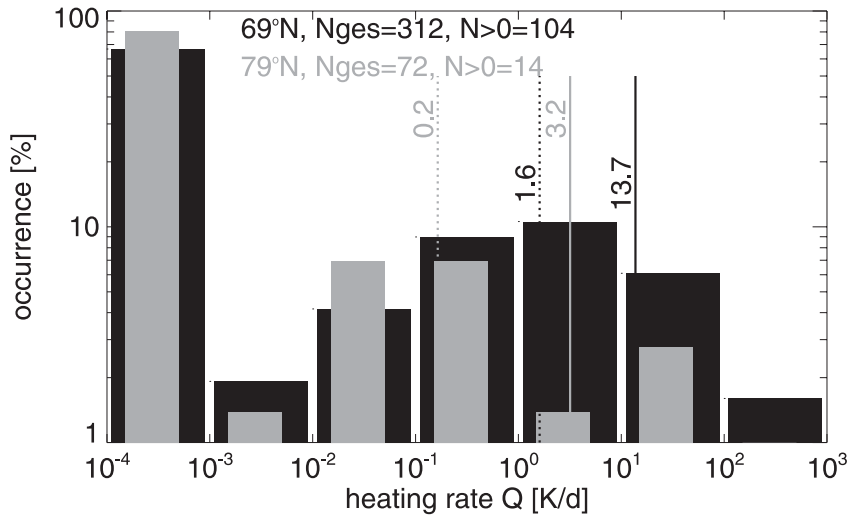

\section{Latitude dependence} of polar turbulence

M. Rapp et al.

Title Page

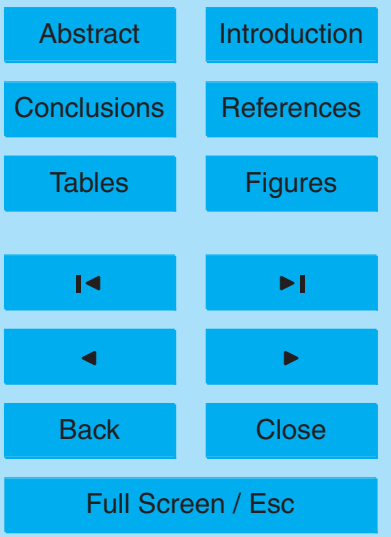

Fig. 2. Histogram of the turbulent heating rates measured at $69^{\circ} \mathrm{N}$ (in black) and $79^{\circ} \mathrm{N}$ (in grey). Measurements which were identified as "non-turbulent" have been counted in the class between $10^{-4}$ and $10^{-3} \mathrm{~K} / \mathrm{d}$. Mean and median values of the measurements with $Q>0$ are indicated with solid and dotted vertical lines, respectively. Finally, we have indicated how many measured values formed the basis for these histograms (Nges) and how many of these were retrieved from spectra showing some turbulence (marked as " $\mathrm{N}>0$ ").
Printer-friendly Version

Interactive Discussion

\section{Full Screen / Esc}




\section{ACPD}

6, 12199-12216, 2006

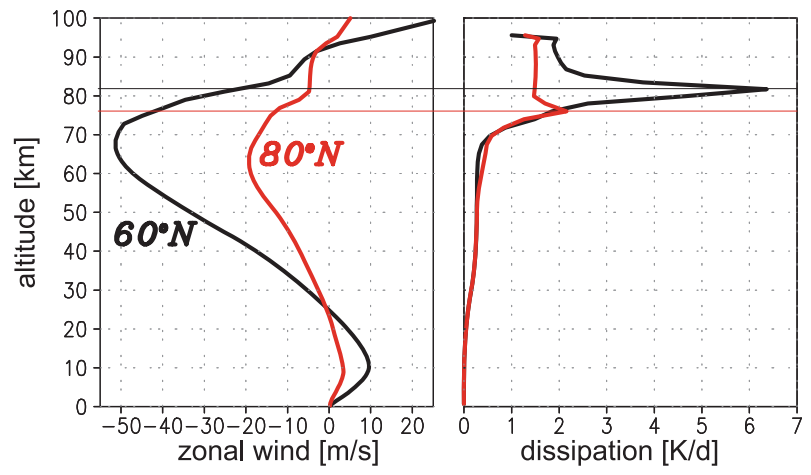

\section{Latitude dependence} of polar turbulence

M. Rapp et al.

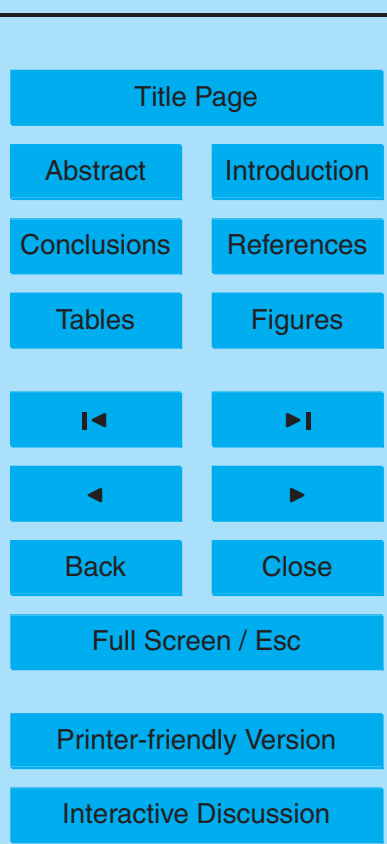

Fig. 3. Left panel: zonal wind profiles at $60^{\circ} \mathrm{N}$ and $80^{\circ} \mathrm{N}$ from a permanent July simulation performed with the Külungsborn Mechanistic Circulation Model as used by Becker et al. (2004). The horizontal lines mark the altitudes at $60^{\circ} \mathrm{N}$ and $80^{\circ} \mathrm{N}$ where the dominating eastward propagating gravity wave with a phase speed of $c \sim 30 \mathrm{~ms}^{-1}$ becomes saturated. Right panel: corresponding profiles of the mean turbulent dissipation of GW kinetic energy, expressed as equivalent heating rates. 


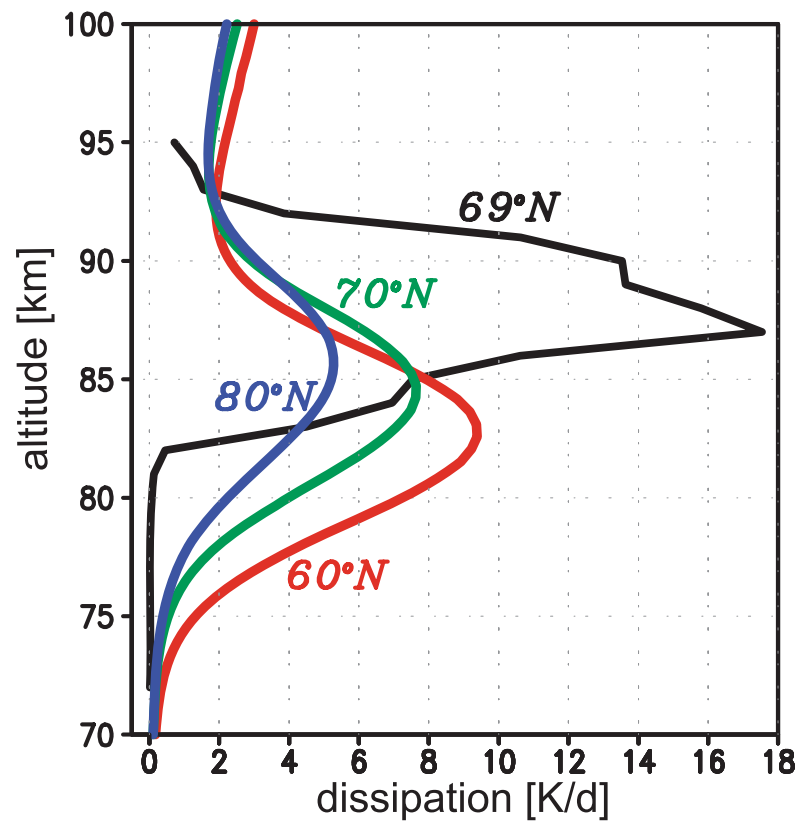

\section{Latitude dependence} of polar turbulence

M. Rapp et al.

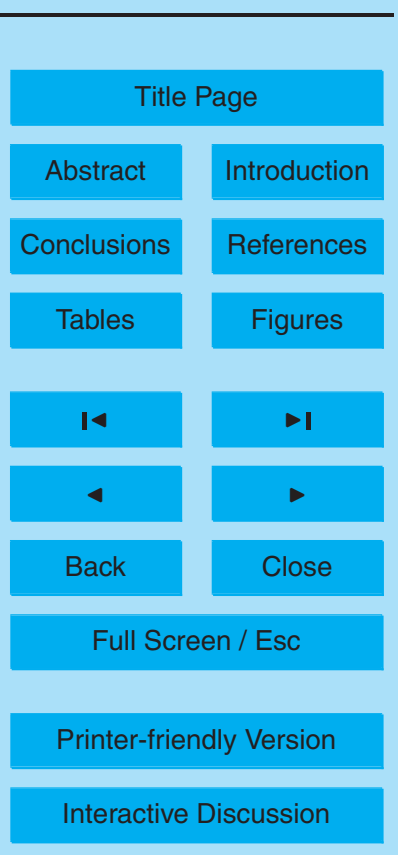




\section{ACPD}

6, 12199-12216, 2006

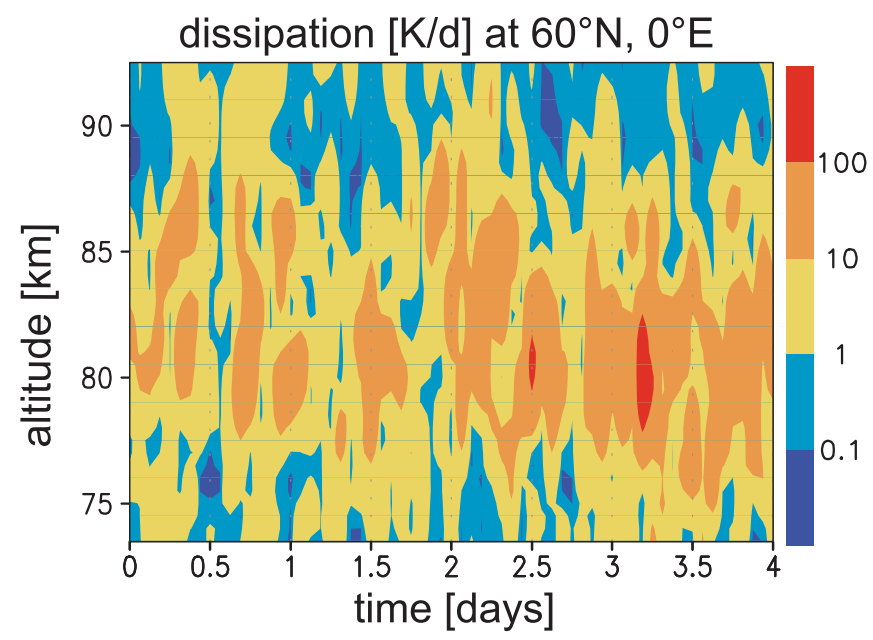

\section{Latitude dependence} of polar turbulence

M. Rapp et al.

Title Page

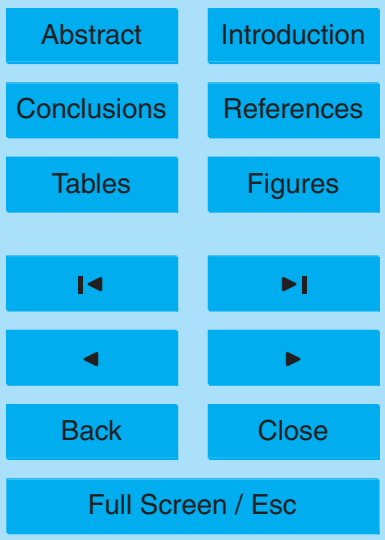

$94 \mathrm{~km}$ taken from the permanent July simulation of Becker and Fritts (2006) at $60^{\circ}$ latitude.

Printer-friendly Version

Interactive Discussion 


\section{ACPD}

6, 12199-12216, 2006

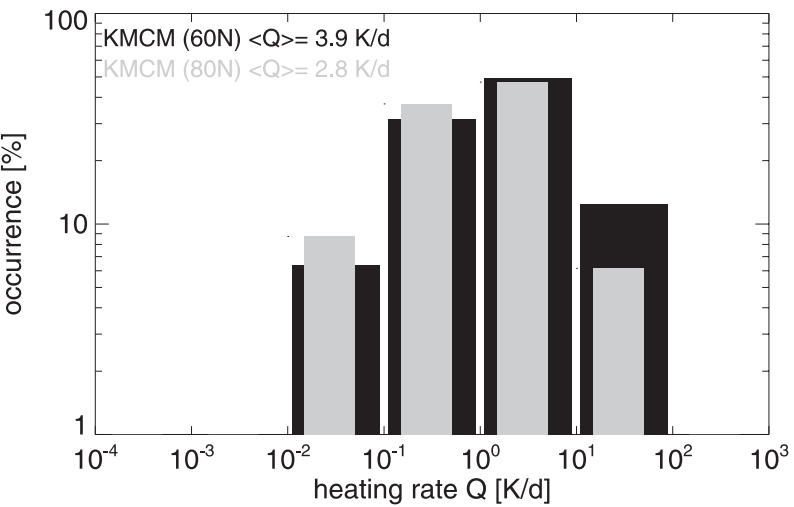

\section{Latitude dependence} of polar turbulence

M. Rapp et al.

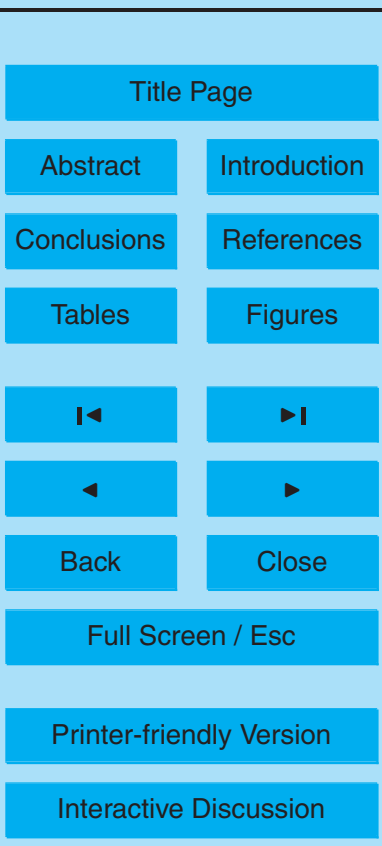

Fig. 6. Histograms of the energy dissipation rates (here shown as equivalent heating rates) at $60^{\circ} \mathrm{N}$ and $80^{\circ} \mathrm{N}$ from the model study of Becker and Fritts (2006) for permanent July conditions. Mean values are indicated in the insert. 